\title{
Users' Experience of Digital Wayfinding Screens: A Uses and Gratification Perspective from South Africa
}

\author{
Thérèse Roux \\ Department of Marketing, Supply Chain and Sport Management, Tshwane University of Technology, Pretoria, South Africa \\ Correspondence should be addressed to Thérèse Roux; rouxat@tut.ac.za
}

Received 14 January 2020; Revised 26 May 2020; Accepted 12 June 2020; Published 7 July 2020

Academic Editor: Marco Porta

Copyright (c) 2020 Thérèse Roux. This is an open access article distributed under the Creative Commons Attribution License, which permits unrestricted use, distribution, and reproduction in any medium, provided the original work is properly cited.

\begin{abstract}
Marketing and business communication researchers have neglected the wayfinding capabilities of digital out-of-home communication in the retailing landscape. The current study focuses on digital wayfinding screens in the South African shopping mall environment. The aim is understanding users' experience of digital wayfinding screens, guided by the uses and gratification theory. Shoppers were interviewed about their views and actions while engaging in the wayfinding process in large upmarket shopping malls. The in-depth semistructured interviews were recorded and then the content was analysed. The findings provide a rich and comprehensive understanding of shoppers' content gratifications and process gratifications when utilising this contemporary medium. The current study identifies four uses and gratifications for digital wayfinding screens: convenient process gratifications, interactive process gratifications, informational content gratification, and entertaining content gratifications. Understanding the gratification dimensions of digital wayfinding screens contributes to contemporary media research and forms the basis of valuable guidelines for practitioners in retail media and design.
\end{abstract}

\section{Introduction}

Digital out-of-home (DOOH) communication remains underresearched [1], notwithstanding novel digital technologies that offer engaging and interactive opportunities to revolutionise the traditional "outdoor" medium [2]. The global DOOH market is predicted to reach 11380 million USD in 2024, growing at a compound annual growth rate of 7.9\% between 2019 and 2024 [3]. DOOH market is expected to continue to expand at a time when the penetration of other digital media has slowed down noticeably [4]. African countries such as Kenya, Ghana, Tanzania, and Nigeria represent some of the most rapidly expanding DOOH markets globally and are projected to continue to expand [5]. South Africa has also realised a substantial growth in the installation of digital screens in various leisure and retail environments [6]. Hence, digital signage in South Africa is projected to represent $43 \%$ of the total out-of-home $(\mathrm{OOH})$ advertising revenue in 2022 [5].

The DOOH media market comprises billboards, transits, street furniture, and place-based media [7]. The focus of this paper is on a specific type of place-based media, namely, digital wayfinding screens in the South African shopping mall environment. Place-based media placed inside public spaces (e.g., medical centres, offices, shopping malls, and airports) offer a wide assortment of beneficial uses and applications (e.g., community information, education, and wayfinding facilities) [1, 8]. Kutnicki [9] emphasises that "directing and orientating of shoppers in public mall space is an essential concern for how citizens in a consumer-based economy, not only judge how to move about freely, but also how they situate those judgments according to prearranged forms of spatial guidance systems, such as wayfinding media." Digital signage with wayfinding screens has been proven to enhance shopping mall attractiveness and enjoyment by offering a sense of direction and decrease the time spent getting lost or looking for intended outlets $[10,11]$.

Despite the attractiveness and increasing variety of DOOH media [4], scholarly research by marketing and business communication scholars remains scant. Kutnicki's [9] narrative literature review on wayfinding print media in 
American retail spaces recommends that wayfinding strategies should be based on how consumer decisions are made and what kind of moods deters consumption. However, this critique focused on printed mall maps and directories and did not collect empirical primary data on digital interactive media. Empirical studies on wayfinding solutions in diverse settings such as health services [12], transit terminals [13]; Fuller [14], and cityscapes [15] show that well-considered wayfinding is crucial to create satisfactory experiences. These studies offer valuable results on how design could be used to positively impact experiences in different settings. It must be noted that they do not empirically examine users' experience of digital wayfinding screens inside the shopping mall environment or consider the uses and gratification (U\&G) theory.

The limited research on this topic originates primarily from the computer science field and relies on mechanical observations to determine the efficiency of the information technology components. Abraham and Kennedy [16], for example, designed real-time computer vision algorithms to test observer-specific advertisements broadcasted on display systems. Corenthy et al. [17] designed a multisensory experience via interactive digital signage with tracking technology and ultrasonic mid-air haptic feedback to improve interactivity of the system, while Ravnik and Solina [18] developed a digital screen audience measurement system using computer vision. Gan et al. [19] examined the effect of combining mobile applications and digital displays to build an indoor position and navigation system and a personalised signage service to offer a more accurate position and marketing information on demand. Despite the potential and technological evolution, displays in public areas seem to be designed without proper consideration of the context, resulting in lower convenience and attention levels [20]. These studies offer valuable insight into the design of technology for DOOH media components and support the need for user evaluation studies.

However, consumer centric studies on DOOH media in retail applications are limited. This might mean missing out on the potential to offer enjoyable consumer experience proven to influence consumers' intention to repatronise shopping malls [21, 22]. Past research conducted by prominent authors in developed countries has concentrated mainly on two broad issues. Some examined consumers' sales response to advertising messages on digital signage inside stores [23-26]. Others examined the potential role of digital signage in contributing to retail atmospherics [27-30]. These studies accentuate the potential role of digital signage when used by retailers and shopping mall managements in enhancing the overall shopping experience. However, none of these studies consider digital wayfinding screens inside the shopping mall environment in an emerging country context.

The objective of this paper is to explore users' experience of digital wayfinding screens guided by the U\&G theory. This study is one of the first to explore shoppers' experience of place-based media with wayfinding capabilities and contributes by extending the U\&G theory to the $5^{\text {th }}$ screen (digital networked screens) [10]. Rubin [31] recently pointed out that U\&G studies would greatly benefit from "increased specificity, especially as attention is turned to new media." Following this advice, the current study focuses on digital wayfinding screens as one of the latest developments in screen evolution.

Meziani and Hussien [11] emphasise the need for studying indoor wayfinding solutions to make it simpler for visitors to efficaciously traverse in malls, airports, clinics, universities, and office blocks. This research contributes to the limited theory on $\mathrm{DOOH}$ communication media and offers a rich and vibrant understanding of how real shoppers in the actual mall environment interact with digital wayfinding screens.

From a practical perspective, this study can inform business, media scholars, multimedia designers, and retailers on consumer centric aspects to consider in order to deliver a satisfying media and mall experience. In the following sections, the U\&G theory and past research on major media displays and wayfinding functions and types are discussed, followed by the research methodology and results. The article is concluded by providing recommendations and directives for future research.

\section{Theoretical Background}

2.1. Uses and Gratification Theory. While there are various aspects of place-based media that can be examined, the study specifically focuses on digital wayfinding screens and explores the user experience by means of the U\&G theory as a theoretical framework. The U\&G theory concentrates on why people use certain media rather than on the content of the media. In contrast to the concern of the "media effects" tradition about "what media do to people," U\&G theory is more focused on "what people do with media," permitting an assortment of reactions and explanations. Gratifications sought reflect the gratifications that people seek and potentially receive from media use. Gratifications attained refer to the satisfaction obtained by active media users [32].

Rubin [33], as one of the prominent pioneers of U\&G studies aimed at understanding electronic and digital media, summarises the five principal assumptions of a modern perspective of U\&G as follows: (i) communication behaviour, including media selection and use, is goal-directed, purposive, and motivated; (ii) people take the initiative in selecting and using communication vehicles to satisfy needs or desires; (iii) a variety of social and psychological factors facilitate communication behaviour; (iv) media compete with other forms of communication for selection, attention, and use to gratify needs or wants; and (v) humans are typically more influential than the media in the relationship, but not always.

The U\&G theory has been a highly influential theory in media research and served as foundation for several empirical studies published in top marketing and business periodicals [34]. Despite some early criticisms, e.g., [35], U\&G media scholars have addressed the main concerns in subsequent publications [32, 36]. Ruggiero [32] even contends that all empirical research efforts studying the potential development of communication theory need to consider the U\&G of the medium. Other scholars 
convincingly argue that modern theories of $U \& G$ have progressed to incorporate concepts such as interactivity, demassification, hypertextuality, and asynchronicity. Interactivity in particular embodies the essential notion of the $U \& G$ concept of active users, since it has been defined as "the degree to which participants in the communication process have control over and can exchange roles in their mutual discourse" [37].

Different dimensions of interactivity are propositioned in the literature. Ha and James [38] differentiate between five user-orientated dimensions of interactivity to improve media fulfilments, namely, (i) playfulness, (ii) choice, (iii) connectedness, (iv) information collection, and (v) reciprocal communication. Ruggiero [32] proposes six key dimensions of interactivity that could be suitable for the $U \& G$ approach to examine cotemporary media, namely, (i) threats, (ii) benefits, (iii) sociability, (iv) isolation, (v) involvement, and (vi) convenience. More recently, Limerick et al. [39] distinguish between low interactivity where users engage via a basic interaction (e.g., reaching out and touching/pointing towards) and high interactivity involving multiple interactions and fully immersive experiences with relevant multimodal feedback (e.g., 3D virtual spaces or game-like experiences).

Sundar and Limperos [36] responded to the calls for conceptual refinement by U\&G theory scholars and developed a taxonomy with four classes of technological affordances in digital media. Affordance from a user perspective refers to the action possibilities that are readily apparent to a user. This taxonomy can be applied to digital wayfinding screens as follows: (i) modality affordance allows different methods of multimedia presentation of content, (ii) agency affordance allows all to be agents or sources of information, (iii) navigability affordance allows users to navigate through the medium via the touch screen, (iv) interactivity affordance allows the user to make real-time changes to the content in the medium. Digital wayfinding screens typically do not allow shoppers to change content; however, this can be done if integrated with social media and mobile phones.

\subsection{Past UઐG Theory Research on Different Media Displays.} The classification of media evolution depends on the discipline in which it is studied and the time period. Scholars in the field of computer science [40] and marketing communications [41] recognise the simultaneous usage of multiple media displays known as multiscreening. Cerny and Donahoo [40] argue that the traditional approach concentrating on a single screen or stream of information is outdated, and they support a multidimensional perspective augmenting the mainstream of information with second screens. The second screen is a display designed to augment primary viewing by providing additional content. These displays are typically interactive, allowing content individualisation, and can even be mobile [40].

Empirical research on second screens can be classified into four streams. The first stream includes studies examining second screen services for entertainment, such as live performances in theatres, movies, or events (e.g., [40]).
Studies related to the second stream consider second screen interaction through social media and interactive technologies [42]. The third stream focuses on the second screen advertising or multiscreening effects on advertising outcomes (e.g., [41, 43]). The fourth stream focuses on the second screens with digital technology helping users to accomplish certain tasks, such as computer-aided, assistant-like applications helping visitors based on their age or disabilities to navigate through a large complex hospital [44]. The aim of the current study is to provide insight into digital placebased media with wayfinding capabilities by exploring its uses and gratifications prevalence. It therefore falls under the fourth stream, when following the above classification of past research streams on second screens.

Marketing and business communication scholars categorise the evolution of screens based on the technology into five stages, namely, $1^{\text {st }}$ screen (cinema), $2^{\text {nd }}$ screen (televisions), $3^{\text {rd }}$ screen (personal computers), $4^{\text {th }}$ screen (mobile devices), and $5^{\text {th }}$ screen (digital networked screens) [10]. This $5^{\text {th }}$ screen, also known as $\mathrm{DOOH}$ media [3], comprises digital boards at point of transit, digital signage inside stores at point of sale, and place-based media at point of wait such as bars, restaurants, gas stations, and health clubs [7]. Based on this categorisation of screen evolution, the current study centres on the $5^{\text {th }}$ screen in the mall environment.

Previous U\&G media research on the five different media screens is summarised in Table 1. The findings of these studies have been classified according to the following three gratification dimensions sought by users of contemporary media [55]: (i) process gratifications when using a particular medium, because they enjoy the process of using the medium; (ii) content gratifications, where consumers use a particular medium for the content it provides; and (iii) social gratifications, where consumers use a particular medium to gratify their need for social interaction.

The table reveals that U\&G theory has been employed in various studies as an appropriate paradigm to explain the motivations and uses of diverse media displays. These studies examined the legal and illegal movie consumption habits of young adults [45], traditional broadcast television to people indoors while they are inside their own homes [46-48], computers connected to the Internet to view social and paid network television $[49,50]$, and factors influencing the use of applications and social networks on smartphones and tablet computers $[52,53]$.

Only one of these studies focused on the $5^{\text {th }}$ screen. Adetunji et al. [54] examined the determinants of audience gratification towards large digital-billboard advertising aimed at commuters in the transit environment. They collected data by conducting a survey among 100 university students. The data were thus based on recall, rather than experience of users when using media in a certain context (e.g., mall space), and did not consider indoor place-based media. In summary, the uses and gratifications of digital place-based media with wayfinding capabilities in public spaces (e.g., malls) were not the focus of past studies.

In practice, several researchers have concurred that the U\&G theory is best suited to examine the use and motivations behind using different media screens. Since it has 
TABLe 1: Past U\&G research on different media displays.

\begin{tabular}{|c|c|c|c|c|}
\hline Author(s) & Aim and methodology & Content gratifications & Process gratifications & Social gratifications \\
\hline \multicolumn{5}{|c|}{$1^{\text {st }}$ screen (cinema/movies) } \\
\hline $\begin{array}{l}\text { Henkel et al. } \\
{[45]}\end{array}$ & $\begin{array}{l}\text { Movie consumption habits of } \\
\text { young adults, legal and illegal film } \\
\text { consumption }\end{array}$ & $\begin{array}{c}\text { Illegal: } \\
\text { Free content } \\
\text { Fast accessibility to films } \\
\text { via the Internet }\end{array}$ & $\begin{array}{c}\text { Legal: } \\
\text { Affective (pleasure } \\
\text { seeking) needs, } \\
\text { personal integrative } \\
\text { (credibility/status seeking) } \\
\text { needs, } \\
\text { tension release (escape } \\
\text { seeking) needs }\end{array}$ & $\begin{array}{c}\text { Social integrative } \\
\text { (participatory through } \\
\text { social networking sites) } \\
\text { needs }\end{array}$ \\
\hline \multicolumn{5}{|c|}{$2^{\text {nd }}$ screen (traditional broadcast television) } \\
\hline $\begin{array}{l}\text { Balci and } \\
\text { Ayhan }[46]\end{array}$ & $\begin{array}{l}\text { Motivations and habits of watching } \\
\text { public TV survey with } 583 \text { people }\end{array}$ & $\begin{array}{l}\text { Information seeking } \\
\text { entertainment }\end{array}$ & $\begin{array}{l}\text { Relaxation, pastime, } \\
\text { escape from social } \\
\text { interaction }\end{array}$ & Companionship \\
\hline $\begin{array}{l}\text { Palmgreen } \\
\text { and Rayburn } \\
\text { [47] }\end{array}$ & $\begin{array}{l}\text { Uses and gratifications and } \\
\text { exposure to public TV }\end{array}$ & $\begin{array}{l}\text { Information } \\
\text { entertainment }\end{array}$ & $\begin{array}{l}\text { Relaxation, to forget, } \\
\text { passing time }\end{array}$ & $\begin{array}{l}\text { Communicatory utility } \\
\text { companionship }\end{array}$ \\
\hline Rubin [48] & $\begin{array}{l}\text { Uses and gratifications to public } \\
\text { TV secondary data analysis }\end{array}$ & $\begin{array}{c}\text { Information } \\
\text { entertainment }\end{array}$ & $\begin{array}{c}\text { Passing time, } \\
\text { consumption/habit }\end{array}$ & Companionship \\
\hline \multicolumn{5}{|c|}{$3^{\text {rd }}$ screen (computer displays connected to the Internet/contemporary digital TV) } \\
\hline Lin et al. [49] & $\begin{array}{l}\text { Motivations for social TV } \\
\text { participation online survey }\end{array}$ & Social infotainment & & Social companionship \\
\hline $\begin{array}{l}\text { Shade et al. } \\
\text { [50] }\end{array}$ & $\begin{array}{l}\text { Uses and gratifications and media } \\
\text { migration for paid network TV } \\
\text { survey method }\end{array}$ & $\begin{array}{l}\text { Enlightenment } \\
\text { entertainment }\end{array}$ & Escape & $\begin{array}{l}\text { Content-congruent } \\
\text { exposure }\end{array}$ \\
\hline $\begin{array}{l}\text { Whiting and } \\
\text { Williams [51] }\end{array}$ & $\begin{array}{l}\text { Uses and gratifications for using } \\
\text { social media, } 25 \text { in-depth } \\
\text { interviews }\end{array}$ & $\begin{array}{l}\text { Information seeking, } \\
\text { entertainment, } \\
\text { surveillance/knowledge } \\
\text { about others }\end{array}$ & $\begin{array}{l}\text { Passing time, relaxation, } \\
\text { communicatory utility, } \\
\text { convenience utility }\end{array}$ & $\begin{array}{l}\text { Social interaction, } \\
\text { expression of opinion, } \\
\text { information sharing }\end{array}$ \\
\hline \multicolumn{5}{|c|}{$4^{\text {th }}$ screen (mobile devices) } \\
\hline Kang [52] & $\begin{array}{l}\text { Factors influencing intention of } \\
\text { mobile app use on smartphones } \\
\text { and tablet computers, } 788 \\
\text { respondents to an online survey }\end{array}$ & $\begin{array}{l}\text { Information } \\
\text { entertainment }\end{array}$ & $\begin{array}{l}\text { Communication seeking } \\
\text { and sharing }\end{array}$ & Social utility \\
\hline Ha et al. [53] & $\begin{array}{l}\text { Identify gratifications driving } \\
\text { mobile SNSs use, } 311 \text { SNSs users }\end{array}$ & $\begin{array}{l}\text { Cognitive and hedonic } \\
\text { gratification }\end{array}$ & Mobile convenience & $\begin{array}{l}\text { Social interactive } \\
\text { gratification }\end{array}$ \\
\hline \multicolumn{5}{|c|}{$5^{\text {th }}$ screen (digital networked screens) } \\
\hline $\begin{array}{l}\text { Adetunji et al. } \\
\text { [54] }\end{array}$ & $\begin{array}{l}\text { Determinants of audience } \\
\text { gratification towards digital- } \\
\text { billboard advertising }\end{array}$ & Informativeness & $\begin{array}{l}\text { Digitalisation, irritation, } \\
\text { location }\end{array}$ & NA \\
\hline
\end{tabular}

been applied in many studies on different media displays, the same theory is used in this study, in the mall environment and within in the context of a developing country. Social gratifications that entail interpersonal communication and social networking [56] offered when using media such as mobile devices [52, 53] and the Internet [49-51] were not included in the current study of the digital wayfinding screens, since they do not offer these types of functions at this stage.

2.3. Wayfinding Settings, Functions, and Types. The following four types of contextual factors considered to be instrumental in effective wayfinding can be found in the literature [57]: (i) visual access to memorable cues or landmarks within or exterior to a building; (ii) level of architectural distinction between different areas of a building that can aid recall and thus also orientation; (iii) signs and number usage offering identification or directional information; and (iv) building formation, which can affect the ability of people to understand the overall layout of the building. José et al. [20] identify specific contextual dimensions influencing viewers' processing of digital public displays, namely, location and spatial arrangement of the display with respect to its environment; activities taking place and tasks performed in the display setting; community engagement; and place identity. They found that most digital displays are not designed taking these contextual factors into consideration. This confirms previous studies observing the lack of situatedness of digital displays and demanding solutions in terms of either the design or the sensing capabilities of digital displays $[56,58]$.

Lidwell et al. [61] define wayfinding as "the process of using spatial and environmental information to navigate to a destination." According to Kutnicki [9], wayfinding media influences how movement is conceptualised within a mall to enable various uses and appropriations aimed at neutralising public anxiety about control and manipulation [9]. 
Wayfinding can thus basically be described as a decisionmaking process applied to address a spatial problem [62]. Fewings [63] classifies wayfinding based on its purpose to reach a specific destination as recreational, resolute, or emergency. Recreational wayfinding, used when time is not limited, offers problem-solving opportunities that can be pleasant and satisfying. With resolute wayfinding the main purpose is to find one's route in the most efficient manner. In emergency wayfinding, reaching one's destination as speedily and as effortlessly as possible is the main purpose.

Wayfinding signage can be divided into five different categories in terms of the functions served [64]: (i) orientation signage, such as "You-Are-Here" maps, orientates viewers; (ii) direction signage employs maps, instructions, or pointers to deliver pathfinding information to get from one location to the other; (iii) identification signage announces the name of a specific item or area; (iv) information signage provides information about a desired destination to customers; and (v) regulatory signs contain instructions where failure to comply constitutes either a legal offence or breaking of safety measures or other directions. Some examples include exit signs and warning signs indicating what to do in an emergency. When applying this categorisation to static signage, this means that different signage types located across a public space are used to perform these functions. The digital nature of the digital wayfinding screens explored in the current study allows all five different categories to be integrated into one medium.

\section{Methodology}

U\&G researchers have identified several "gratifications" over the past 60 years by using the classic two-step methodological approach of qualitative exploration, followed by quantitative surveys $[31,65,66]$. For this paper a qualitative research approach was followed to understand actual shoppers' gratifications with digital wayfinding screens in the mall environment. Nonprobability quota purposive sampling was applied to recruit shoppers in two large upmarket shopping malls with modern wayfinding place-based media. Purposeful sampling means the researcher purposefully selects individuals, groups, and settings that maximise understanding of the underlying phenomenon. Patton [67] advises that this sampling is suitable when the goal is not to generalise to a population, but rather to obtain insights into a phenomenon or events. For the current study quota sampling was applied to reflect the same proportions of individuals as the entire population with respect to demographical characteristics of the shoppers in the malls. The aim was not to generalise the results to a larger population of shoppers.

A total of 30 individuals meeting a quota reflecting the profile of the respective malls agreed to participate in the interviews. The number of participants is similar to that in other qualitative studies on digital and social media platforms (e.g., [20, 51]). The malls of South Africa were selected based on the large size and consequent long distances between stores and variety of stores. Participants were chosen according the shoppers' profile supplied by the mall owners and recruited by interviewers from the general mall area. Sample selection was based on three criteria; that is, subjects: (a) used wayfinding screens before; (b) were older than 18 years so that they can provide informed consent; and (c) were not employees of advisers, mall owners, or retailers to minimise bias.

The interviews were guided by a semistructured discussion guide and different stimuli in the form of maps, information, and advertising displayed on digital wayfinding screens. The shoppers were interviewed about their thoughts and their actions during their wayfinding experience. The recordings were content-analysed. Coding of the interviews was informed by the three-phase process recommended by Campbell et al. [68]. The first phase involved development of a coding scheme based on five of the transcripts by the researcher and a co-coder. During phase two, disagreements on codes were discussed and adjusted where needed. The transcripts were then recoded according to the adjusted coding scheme. In the third phase, the researcher coded the full set of transcripts.

To limit error in the qualitative design and achieve rigor, Guba's guidelines for ensuring trustworthiness in qualitative studies [69] were applied. Content analysis, which involves intensive searching through data in order to identify patterns that might occur more than once [70], was used to decipher the interviews. Sorting and theme generation facilitated the listing of key ideas and recurrent themes. Consistency and systematic analysis were ensured by developing a coding scheme to be used as a standard template, as suggested by Morgan and Krueger [71].

\section{Results and Discussion}

4.1. Target Group. Table 2 shows that most of the participants were female (63\%), with $37 \%$ being male. In terms of age, the breakdown is as follows: $50 \%$ were $18-30$ years; $27 \%$ were 31-40 years; and 23\% were older than 41 . Since a quota sample was applied, the demographic features of the participants closely reflected the profile of the shoppers supplied.

4.2. Findings. Gratifications experienced with digital wayfinding screens were considered in terms of the two major gratification types required by users of contemporary media, namely, process gratifications and content gratifications [55]. The major themes of the findings are presented in Table 3.

4.2.1. Process Gratifications. Process gratification relates to the experience of the media usage process and is concerned with the actual use of the medium itself [56]. The interviews revealed that the features of this wayfinding medium contribute to convenient and interactive process gratifications in the shopping mall environment. These themes are discussed below. 
TABLE 2: Demographic profile of the participants.

\begin{tabular}{|c|c|c|c|}
\hline Participant & Mall & Gender & Age \\
\hline $\mathrm{P} 1$ & 1 & Female & $18-30$ \\
\hline $\mathrm{P} 2$ & 1 & Male & $41+$ \\
\hline P3 & 1 & Male & $41+$ \\
\hline $\mathrm{P} 4$ & 1 & Female & $18-30$ \\
\hline P5 & 1 & Male & $31-40$ \\
\hline P6 & 1 & Female & $18-30$ \\
\hline P7 & 1 & Female & $31-40$ \\
\hline P8 & 1 & Female & $31-40$ \\
\hline P9 & 2 & Male & $31-40$ \\
\hline P10 & 2 & Female & $18-30$ \\
\hline $\mathrm{P} 11$ & 2 & Male & $41+$ \\
\hline P12 & 2 & Female & $31-40$ \\
\hline P13 & 2 & Female & $18-30$ \\
\hline P14 & 2 & Female & $18-30$ \\
\hline P15 & 2 & Female & $18-30$ \\
\hline P16 & 2 & Female & $41+$ \\
\hline P17 & 2 & Male & $18-30$ \\
\hline P18 & 2 & Male & $31-40$ \\
\hline P19 & 3 & Female & $18-30$ \\
\hline $\mathrm{P} 20$ & 3 & Female & $18-30$ \\
\hline P21 & 3 & Male & $41+$ \\
\hline P22 & 3 & Female & $18-30$ \\
\hline P23 & 3 & Male & $41+$ \\
\hline $\mathrm{P} 24$ & 3 & Female & $18-30$ \\
\hline P25 & 3 & Male & $18-30$ \\
\hline P26 & 3 & Female & $18-30$ \\
\hline P27 & 3 & Female & $31-40$ \\
\hline P28 & 3 & Female & $31-40$ \\
\hline P29 & 3 & Male & $41+$ \\
\hline P30 & 3 & Female & $18-30$ \\
\hline
\end{tabular}

Gender: female, 19 (63\%); male, 11 (37\%). Age: $18-30$ years, 15 (50\%); $31-40$ years, 8 (27\%); $41+$ years, 7 (23\%).

4.2.2. Convenient Process Gratifications. This sort of process gratification was mentioned by $90 \%$ of the respondents and is defined as the ease of finding a specific destination or offering in the mall space. The title of this theme comes from Ha et al.'s study [53] on the uses and gratifications for mobile media use and was also identified by Ruggiero [32] as one of the main dimensions of interactivity offered by contemporary media platforms.

The interviews offered substantiation of recreational and resolute wayfinding. Several of the respondents discussed situations suggesting satisfaction with recreational wayfinding. These shoppers enjoy the hedonist shopping, the shopping space, and the sensorial excitement. The hedonic experience of wayfinding was thus more important than the functional value of getting from shop A to shop B. These respondents typically reported, "I enjoy browsing you know. It is fun to go through the stores and offers on the touch screen displays."

Other shoppers regard resolute wayfinding, showing the most efficient route [63] to certain products, stores, and facilities, as crucial. These types of shoppers strive to complete utilitarian shopping tasks in an efficient way, and therefore the functional value of reaching a shop stocking the required products is likely to be critical. One individual, for example, mentioned that he needed "clarifying about the amount of time it takes for you to get to the destination that you want to arrive at."

4.2.3. Interactive Process Gratifications. This human-message interaction gratification was mentioned by $70 \%$ of the respondents. The title of this theme comes from Ko et al.'s study [72] on Internet uses and gratifications of interactive advertising.

The digital wayfinding screens offered interactivity via features, such as the speed at which information is transmitted and feedback received, and variety of sensory activation. Respondents mentioned different ways in which they interact via the touch screens. Some of them explained how they use the alphabetical and categorical search functions: "There are different options to get a specific shop, like by using the alphabet or by searching specific categories. So, it makes my chances better to find something very specific or a specific type of shop, even if I do not know the exact name of a shop." Others mentioned that they prefer to use instructions on the screen: "It is easy and quick to use because all the instructions are clear and it does not seem to be too complicated, all you must do is touch the screen and follow the instructions."

Valuable comments were made regarding the need for context interactivity that considers the environment in which interactive communication takes place [73]. One individual suggested adding features for "notifying the user that the restaurant is full or empty while the user is browsing through the menu of the way finder." Another person recommended including an interactive feature that "directs you exactly to where the nearest bathrooms are from you." These requests of the interviewed shoppers suggest a need to move from the level of basic interaction towards high interactivity involving multiple interactions and immersive experiences with relevant multimodal feedback, as suggested by Corenthy et al. [17].

4.2.4. Content Gratifications. Content gratifications are obtained from the content carried by the medium and are concerned with the messages carried by the medium [56]. The results revealed that digital wayfinding screens were regarded as prospective sources of informational and entertaining content in the mall environment. These two themes are discussed below.

4.2.5. Informational Content Gratification. This was mentioned by $80 \%$ of the respondents. The participants appreciated newsworthy and promotional messages. Some of their comments were as follows: "it informs me about new stores in the mall and helps me knowing what is up" and "it allows me to get various information effectively... what are the specials, events, operating hours, stores, maps." The gratification of the informativeness offered by digital wayfinding screens is aligned with the audience gratification dimensions reported for digital-billboard advertising by Adetunji et al. [54]. This is also similar to the study by Pantano [74] recognising the functional value delivered by interactive 
TABle 3: Major themes of the findings.

Mentioned by number of participants Mentioned by \% of participants

Process gratifications: experience when using the digital wayfinding screens features

(i) Convenient process gratifications

(ii) Interactive process gratifications

splayed on the digital wayfinding screens

Content gratifications: obtained by vie
(i) Informational content gratification

(ii) Entertaining content gratifications

technologies inside store windows as main factor contributing to positive evaluations.

However, the experiences of the shopper interviewed were not always positive. These types of negative encounters due to the inability of digital wayfinding screens to sense and react to the environment were also identified in studies examining digital public displays in other settings $[20,58,60]$. Specific advice and clear expectations were articulated by some of the respondents to improve content customisation. Areas of recommendation included displaying relevant community communication, news, guidance on shopping offerings, and local events:

"But they can add some local information about the city or like current news. Or what about sports news or results?"

"...update it immediately...if there is arrival of new stock like fashion or technology items - it will attract some of my friends who like to be the fashion leaders."

"Get advertisements from the stores that are actually in the mall, for example, have pop up ads on the digital screen of stores that one can find inside the shopping mall."

4.2.6. Entertaining Content Gratifications. More than half (57\%) of respondents mentioned that they consult digital wayfinding screens for entertaining content. The entertaining content gratifications identified in this article are analogous to the dimension of "being relax and be entertained" in a study by Elmashhara and Soares [75] on shopping mall entertainment. This finding also complements previous studies on interactive technologies, reporting that the integrating of enjoyable features can enhance consumers' shopping experience $[74,76]$.

However, the interviews also revealed a lack of entertaining content gratifications and some suggestions on how to improve the hedonic value offered. One individual, for example, said, "We need something for the kids you know, because kids are also running around a mall as well, you know, so maybe some entertainment for them while the parents do the shopping."

It was recommended that entertainment content such as music videos, sport news, and information about cultural events in the area should be displayed in leisure and eating spaces of the malls. These content preferences reflected certain demographical differences in terms of shoppers. The younger participants typically preferred lively music and made comments such as the following: "I would like that it plays urban and upbeat music, because I like music and I find music entertaining. If maybe you were sad and you entered the mall events area, by hearing sound or music, it could change your mood. Good music puts me in a good mood just like when shopping for fashion or eating with my friends." The males typically appreciated sport being displayed and suggested that they expect "sports news or results delivering live match footage." Many female individuals mentioned that they appreciated cultural news and believed that this can be done better using social media: "I want to see some highlights of local events, art shows and festivals. They can basically stream live social media feeds from Facebook, Twitter or Instagram on the screens."

This potential of displaying hedonic content on digital wayfinding screens inside public mall spaces confirms the value of second screen services for entertainment such as live performances in theatres, movies, or events alluded to in past research [40]. However, the findings of the current study act as a warning against the practice of placing boring and trivial content.

\section{Conclusion}

This paper demonstrates the value and usefulness of the $U \& G$ theory to researching the $5^{\text {th }}$ screen, as the most recent evolution in screen technology [10]. The application of the U\&G theory helped to understand users' experience of digital wayfinding screens. The findings from the interviews provided a rich and comprehensive understanding of shoppers' content and process gratifications when utilising this contemporary medium. The current study identified four uses and gratifications for digital wayfinding screens. The uses and gratifications found in this study are convenient process $(90 \%)$, informational content $(80 \%)$, interactive process $(70 \%)$, and entertaining content $(57 \%)$.

This research contributes to the existing literature in specific ways. First, this article offers a cohesive review of past $U \& G$ research on the major media screen types. Second, this article confirms to academics and practitioners that the U\&G theory still has significance in terms of contemporary digital media, and argues that $\mathrm{DOOH}$ communication media ought to be given greater standing in business and marketing management fields. Third, the article's qualitative approach contributes methodologically by providing a rich and vibrant understanding of how and why shoppers use digital wayfinding screens, rather than just surveying students based on the recall of media exposure. Last, this research provides academics with several future research opportunities and the business community with specific suggestions on how to improve user satisfaction with this novel media in the shopping mall context. 
5.1. Managerial Recommendations. From the findings of this research, some recommendations to improve the experiences with digital wayfinding screens can be made. Convenient process gratifications can be enhanced by designing digital wayfinding content and functions to satisfy those seeking hedonic shopping experiences as well as those preferring to obtain functional values. The current findings imply that, in place-based media, the complexity brought by technology may be somehow obliterating elements of design that are key enablers for situatedness [20]. Technology to enhance interactive process gratifications should therefore be explored. This can be in the form of digital wayfinding with the ability to support social media and mobile phone integration to deliver maps. This integration can, for example, be used to send interactive maps with instructions to shoppers' phones. Businesses considering these types of technologies should reflect on consumers' attitudes and privacy concerns before spending money on their implementation. These technologies should only be targeted at shoppers opting in and giving permission to receive information and tailored messages from social media platforms to their mobile devices.

To improve content gratification of digital wayfinding screens, constant and well-timed information is crucial. Viewers are more likely to enjoy content that is relevant, interesting, and attractive [11]. The characteristics and situation of the targeted audience must thus be considered when developing gratifying content. Entertaining content could be effective for shoppers who are younger, females interested in culture, or those just browsing in the mall. Information-based functional content might be more suitable for task-orientated or promotional seekers who shop in the mall seeking specific products or brands.

Demassification implies that contemporary consumers, with the power to select from a wide variety of options, prefer individualised customised modes of communication [32]. In contrast to traditional mass media, contemporary media is expected to offer selectivity through newer technologies that enable viewers to customise content based on their needs and the context. Digital screens should be far more dynamic and much more prone to being interactive or reactive to the situation around them. Contextualisation, in terms of digital wayfinding screens, could be implemented by incorporating sensors and technologies that adapt the content displayed on the screens based on the specific context such as time, location, demographics, and consumer preferences. This can be implemented by integrating Bluetooth device detection systems; reflective sign systems that use cameras and image processing to detect audiences' reactions and characteristics to automatically adjust content; and near-field communication (NFC) technology allowing content to be shared with viewers when they touch an NFC tag on the digital media display with their mobile phone $[2,7,77]$.

5.2. Limitations and Directions for Future Research. Just like past analyses, the current study is not without limitations. The scope at this stage was limited to digital wayfinding screens in upmarket malls. Since the aim was to understand users' experience of digital wayfinding screens, these experiences were not quantified. Further research is therefore necessary. This qualitative exploration phase could be followed up by quantitative surveys to implement a classical two-step methodological approach.

A promising potential research direction could be to examine digital wayfinding screens placed at other locations such as airports, train stations, museums, galleries, and even tourist attractions. In future, business researchers could join forces with those in the computer sciences to design and implement mechanical observations and experiments to examine the influence of different interaction levels. This could, for example, be to compare the effect of low engagement via basic interaction (e.g., typing in alphabetical searches) with that of high interaction levels (e.g., interactive maps or indoor position tracking systems integrated via mobile devices) on consumers' emotional, mental, and behavioural responses.

Future studies could also include quantitative analysis of search patterns and usage of digital wayfinding screens across locations and time. The acceptance of new interactive technologies, such as audience-driven mobile integrations and live feeds of events, might also offer alternative future research agendas.

\section{Data Availability}

The actual interview data used to support the findings of this study have not been made available to protect the identity of the participants.

\section{Disclosure}

The funder was not involved in manuscript writing, editing, approval, or publishing decision.

\section{Conflicts of Interest}

The author has no conflicts of interest regarding this publication.

\section{Acknowledgments}

The author would like to thank Opinions Solutions for providing access to shoppers to collect data for this paper. This study was supported in part by the National Research Foundation of South Africa (grant no. 99338).

\section{References}

[1] C. R. Taylor, "Creating win-win situations via advertising: new developments in digital out-of-home advertising," International Journal of Advertising, vol. 34, no. 2, pp. 177-180, 2015.

[2] C. Bauer, N. Kryvinska, and C. Strauss, The Business with Digital Signage for Advertising, Springer, New York, NY, USA, 2016.

[3] Marketwatch, "Digital out of home (DOOH) market 2019 global industry size, demand, growth, analysis, share, revenue, manufacturers and forecast 2027," 2019, https://www. marketwatch.com/press-release/digital-out-of-home-doohmarket-2019-global-industry-size-demand-growth-analysisshare-revenue-manufacturers-and-forecast-2027-2019-07-29. 
[4] K. Sutton, "Digital advertising growth will slow this year, Magna report predicts," 2019, https://magnaglobal.com/digitaladvertising-growth-will-slow-this-year-magna-report-predicts/.

[5] PriceWaterhouseCoopers, "Entertainment and media outlook 2018-2022: an African perspective," 2018, https://www.pwc. co.za/en/assets/pdf/entertainment-and-media-outlook-20182022.pdf.

[6] S. Liebenberg, "Out-of-home advertising," 2012, https://www. pwc.co.za/en/assets/pdf/enm-20120-chapter11.pdf.

[7] A. T. Roux, "Industry perspectives on digital out-of-home advertising in South Africa," Communicare: Journal for Communication Sciences in Southern Africa, vol. 37, no. 1, pp. 17-37, 2018.

[8] H. Huang, G. Gartner, J. M. Krisp, M. Raubal, and N. Van de Weghe, "Location based services: ongoing evolution and research agenda," Journal of Location Based Services, vol. 12, no. 2, pp. 63-93, 2018.

[9] S. Kutnicki, "Wayfinding media and neutralizing control at the shopping mall," Critical Studies in Media Communication, vol. 35, no. 5, pp. 401-419, 2018.

[10] K. Kelsen, Unleashing the Power of Digital Signage: Content Strategies for the 5th Screen, Elsevier, Amsterdam, Netherlands, 2010.

[11] R. Meziani and H. Ali Hussien, "A study on the space layout and configuration of shopping malls in relation to pedestrian movement behavior-case of UAE," International Review for Spatial Planning and Sustainable Development, vol. 5, no. 3, pp. 53-65, 2017.

[12] E. J. Short, S. D. Reay, and R. A. Douglas, "Designing wayfinding systems in healthcare: from exploratory prototyping to scalable solutions," Design for Health, vol. 3, no. 1, pp. 180-193, 2019.

[13] S. A. Cheraghi, V. Namboodiri, and L. Walker, "Guide beacon: beacon-based indoor wayfinding for the blind, visually impaired, and disoriented," in Proceedings of the 2017 IEEE International Conference on Pervasive Computing and Communications (PerCom), IEEE, Kona, HI, USA, pp. 121130, March 2017.

[14] G. Fuller, "The arrow-directional semiotics: Wayfinding in transit," Social semiotics, vol. 12, no. 3, pp. 231-44, 2002.

[15] C. D. Murray, J. Bowers, A. West, S. Pettifer, and S. Gibson, "Navigation, wayfinding and place experience within a virtual city," Presence: Teleoperators and Virtual Environments, vol. 9, no. 5 , pp. $438-451,2000$.

[16] R. E. Abraham and M. R. Kennedy, "Intelligent digital signage system based on gender identification," in Intelligent Embedded Systems, D. Thalmann, N. Subhashini, K. Mohanaprasad, and M. S. Bala Murugan, Eds., pp. 251-262, Springer, Singapore, 2018.

[17] L. Corenthy, M. Giordano, R. Hayden et al., "Touchless tactile displays for digital signage: mid-air haptics meets large screens," in Proceedings of the Extended Abstracts of the 2018 CHI Conference on Human Factors in Computing Systems, p. D103, April 2018.

[18] R. Ravnik and F. Solina, "Interactive and audience adaptive digital signage using real-time computer vision," International Journal of Advanced Robotic Systems, vol. 10, no. 107, pp. 1-7, 2013.

[19] C. C. Gan, Y. J. Lee, and K. W. Lien, "An indoor position system based on dynamic digital signage and mobile devices," in Proceedings of the 2018 1st International Cognitive Cities Conference (IC3), Institute of Electrical and Electronics Engineers, Okinawa, Japan, pp. 186-187, August 2018.
[20] R. José, N. Otero, and J. Cardoso, "Dimensions of situatedness for digital public displays," Advances in Human-Computer Interaction, vol. 2014, Article ID 474652, 11 pages, 2014.

[21] Y. K. Kim, "Consumer value: an application to mall and Internet shopping," International Journal of Retail \& Distribution Management, vol. 30, no. 12, pp. 595-602, 2002.

[22] H. Singh and S. Prashar, "Anatomy of shopping experience for malls in Mumbai: a confirmatory factor analysis approach," Journal of Retailing and Consumer Services, vol. 21, no. 2, pp. 220-228, 2014.

[23] R. R. Burke, "Behavioral effects of digital signage," Journal of Advertising Research, vol. 49, no. 2, pp. 180-185, 2009.

[24] H. Lee and C.-H. Cho, "An empirical investigation on the antecedents of consumers' cognitions of and attitudes towards digital signage advertising," International Journal of Advertising, vol. 38, no. 1, pp. 97-115, 2019.

[25] A. L. Roggeveen, J. Nordfält, and D. Grewal, "Do digital displays enhance sales? Role of retail format and message content," Journal of Retailing, vol. 92, no. 1, pp. 122-131, 2016.

[26] K. Willems, M. Brengman, and S. Van De Sanden, "In-store proximity marketing: experimenting with digital point-ofsales communication," International Journal of Retail \& Distribution Management, vol. 45, no. 8, pp. 910-927, 2017.

[27] C. Dennis, J. Joško Brakus, and E. Alamanos, "The wallpaper matters: digital signage as customer-experience provider at the Harrods (London, UK) department store," Journal of Marketing Management, vol. 29, no. 3-4, pp. 338-355, 2013.

[28] C. Dennis, J. J. Brakus, S. Gupta, and E. Alamanos, “The effect of digital signage on shoppers' behaviour: the role of the evoked experience," Journal of Business Research, vol. 67, no. 1, pp. 2250-2257, 2014.

[29] C. Dennis, R. Michon, J. J. Brakus, A. Newman, and E. Alamanos, "New insights into the impact of digital signage as a retail atmospheric tool," Journal of Consumer Behaviour, vol. 11, no. 6, pp. 454-466, 2012.

[30] C. Dennis, A. Newman, R. Michon, J. J. Brakus, and L. T. Wright, "Modeling shopper responses to retail digital signage," Advances in Marketing, Customer Relationship Management, and E-Services, IGI Global, Hershey, PA, USA, pp. 41-69, 2011.

[31] A. M. Rubin, "Uses and gratifications: an evolving perspective on media effects," in The SAGE Handbook of Media Processes and Effects, R. L. Nabi and M. B. Oliver, Eds., pp. 147-159, SAGE, Washington, DC, USA, 2009.

[32] T. E. Ruggiero, "Uses and gratifications theory in the 21st century," Mass Communication and Society, vol. 3, no. 1, pp. 3-37, 2000.

[33] A. M. Rubin, "Media uses and effects: a uses-and-gratifications perspective," in LEA's Communication Series. Media Effects: Advances in Theory and Research, J. Bryant and D. Zillmann, Eds., pp. 417-436, Lawrence Erlbaum Associates, New Jersey, NJ, USA, 1994.

[34] J. A. Avant, K. Kim, and J. L. Hayes, "Thirty years of advertising research in leading communication and marketing journals: learning from the parent disciplines," Journal of Current Issues \& Research in Advertising, vol. 38, no. 1, pp. 44-64, 2017.

[35] P. Elliott, "Uses and gratifications research: a critique and a sociological alternative," in The Uses of Mass Communications: Current Perspectives on Gratifications Research, J. G. Blumler and E. Katz, Eds., pp. 249-268, Sage, Beverly Hills, CA, 1974. 
[36] S. S. Sundar and A. M. Limperos, "Uses and grats 2.0: new gratifications for new media," Journal of Broadcasting \& Electronic Media, vol. 57, no. 4, pp. 504-525, 2013.

[37] F. Williams, R. E. Rice, and E. M. Rogers, Research Methods and the New Media, Free Press, New York, NY, USA, 1988.

[38] L. Ha and E. L. James, "Interactivity reexamined: a baseline analysis of early business web sites," Journal of Broadcasting \& Electronic Media, vol. 42, no. 4, pp. 457-474, 1998.

[39] H. Limerick, R. Hayden, D. Beattie, O. Georgiou, and J. Müller, "User engagement for mid-air haptic interactions with digital signage," in Proceedings of the 8th ACM International Symposium on Pervasive Displays, pp. 15-21, ACM, Palermo, Italy, June 2019.

[40] T. Cerny and M. J. Donahoo, "Second screen engagement of event spectators," Advances in Human-Computer Interaction, vol. 2018, Article ID 3845123, 20 pages, 2018.

[41] C. M. Segijn, H. A. M. Voorveld, and E. G. Smit, "How related multiscreening could positively affect advertising outcomes," Journal of Advertising, vol. 46, no. 4, pp. 455-472, 2017.

[42] H. Gil de Zúñiga and J. H. Liu, "Second screening politics in the social media sphere: advancing research on dual screen use in political communication with evidence from 20 countries," Journal of Broadcasting \& Electronic Media, vol. 61, no. 2, pp. 193-219, 2017.

[43] C. M. Segijn, H. A. M. Voorveld, and E. G. Smit, "The underlying mechanisms of multiscreening effects," Journal of Advertising, vol. 45, no. 4, pp. 391-402, 2016.

[44] M. Macik, E. Lorencova, Z. Mikovec, and O. Rakusan, "Software architecture for a distributed in-hospital navigation system," in Proceedings of the 2015 Conference on research in adaptive and convergent systems-RACS, pp. 369-375, ACM, Prague, Czech Republic, October 2015.

[45] L. Henkel, M. James, and N. Croce, "Would you like popcorn with that download? a uses and gratifications study into the motivations of legal and illegal film consumption," Quarterly Review of Film and Video, vol. 33, no. 1, pp. 46-63, 2016.

[46] S. Balci and B. Ayhan, "Patterns of television viewing behavior in Kyrgyzstan: a perspective of uses and gratifications," Bilig, vol. 75, p. 275, 2015.

[47] P. Palmgreen and J. D. Rayburn, "Uses and gratifications and exposure to public television," Communication Research, vol. 6, no. 2, pp. 155-179, 1979.

[48] A. M. Rubin, "Television uses and gratifications: the interactions of viewing patterns and motivations," Journal of Broadcasting, vol. 27, no. 1, pp. 37-51, 1983.

[49] J.-S. Lin, K.-J. Chen, and Y. Sung, "Understanding the nature, uses, and gratifications of social television: implications for developing viewer engagement and network loyalty," Journal of Broadcasting \& Electronic Media, vol. 62, no. 1, pp. 1-20, 2018.

[50] D. D. Shade, S. Kornfield, and M. B. Oliver, "The uses and gratifications of media migration: investigating the activities, motivations, and predictors of migration behaviors originating in entertainment television," Journal of Broadcasting \& Electronic Media, vol. 59, no. 2, pp. 318-341, 2015.

[51] A. Whiting and D. Williams, "Why people use social media: a uses and gratifications approach," Qualitative Market Research: An International Journal, vol. 16, no. 4, pp. 362-369, 2013.

[52] S. Kang, "Factors influencing intention of mobile application use," International Journal of Mobile Communications, vol. 12, no. 4, pp. 360-379, 2014.

[53] Y. W. Ha, J. Kim, C. F. Libaque-Saenz, Y. Chang, and M.-C. Park, "Use and gratifications of mobile SNSs: Facebook and KakaoTalk in Korea," Telematics and Informatics, vol. 32, no. 3, pp. 425-438, 2015.

[54] R. R. Adetunji, M. Yazam, and S. S. Nurin, "Assessing audiences' satisfaction of advertising digital-billboard: AU \& G theoretical perspective," in Proceedings of the 2nd International Conference on Arts, Social Sciences \& Technology, Social Science Research Network, Penang, Malaysia, March 2012.

[55] T. F. Stafford, M. R. Stafford, and L. L. Schkade, "Determining uses and gratifications for the Internet," Decision Sciences, vol. 35, no. 2, pp. 259-288, 2004.

[56] S. K. Roy, "Internet uses and gratifications: a survey in the Indian context," Computers in Human Behavior, vol. 25, no. 4, pp. 878-886, 2009.

[57] M. J. Kim, X. Wang, S. Han, and Y. Wang, "Implementing an augmented reality-enabled wayfinding system through studying user experience and requirements in complex environments," Visualization in Engineering, vol. 3, no. 1, pp. 14-25, 2015.

[58] H. Brignull and Y. Rogers, "Enticing people to interact with large public displays in public spaces," in Proceedings of the Interact, pp. 17-24, Zurich, Switzerland, September 2003.

[59] E. M. Huang, A. Koster, and J. Borchers, "Overcoming assumptions and uncovering practices: when does the public really look at public displays?" in International Conference on Pervasive Computing, pp. 228-243, Springer, Berlin, Heidelberg, 2008.

[60] J. Müller, D. Wilmsmann, J. Exeler et al., "May. Display blindness: the effect of expectations on attention towards digital signage," in 7th International Conference on Pervasive Computing Proceedings, H. Tokuda, M. Beigl, A. Friday, A. J. B. Brush, and Y. Tobe, Eds., pp. 1-8, Springer, Berlin, Heidelberg, 2009.

[61] W. Lidwell, K. Holden, and J. Butler, Universal Principles of Design, Rockport, Minneapolis, MN, USA, 2003.

[62] R. Passini, "Wayfinding: a conceptual framework," Urban Ecology, vol. 5, no. 1, pp. 17-31, 1981.

[63] R. Fewings, "Wayfinding and airport terminal design," Journal of Navigation, vol. 54, no. 2, pp. 177-184, 2001.

[64] S.-Y. Tzeng and J.-S. Huang, "Spatial forms and signage in wayfinding decision points for hospital outpatient services," Journal of Asian Architecture and Building Engineering, vol. 8, no. 2, pp. 453-460, 2009.

[65] B. S. Greenberg, Edited by J. G. Blumler, Ed., "Gratifications of television viewing and their correlates for British children," in The uses of Mass Communications: Current Perspectives on Gratifications Research, E. Katz, Ed., pp. 71-92, Sage, Beverly Hills, CA, USA, 1974.

[66] K. Lucas and J. L. Sherry, "Sex differences in video game play:", Communication Research, vol. 31, no. 5, pp. 499-523, 2004.

[67] M. Q. Patton, Qualitative Research \& Evaluation Methods: Integrating Theory and Practice, Sage publications, Thousand Oaks, CA, USA, 2014.

[68] J. L. Campbell, C. Quincy, J. Osserman, and O. K. Pedersen, "Coding in-depth semi structured interviews: problems of unitization and intercoder reliability and agreement," Sociological Methods \& Research, vol. 42, no. 3, pp. 94-320, 2013.

[69] T. A. Schwandt, Y. S. Lincoln, and E. G. Guba, "Judging interpretations: but is it rigorous? trustworthiness and authenticity in naturalistic evaluation," New Directions for Evaluation, vol. 2007, no. 114, pp. 11-25, 2007.

[70] R. Tesch, Qualitative Research: Analysis Types and Software Tools, Falmer Press, Hampshire, UK, 1990.

[71] D. L. Morgan and R. A. Krueger, The Focus Group Kit, Sage Publications, Thousand Oaks, CA, USA, 1998. 
[72] H. Ko, C.-H. Cho, and M. S. Roberts, "Internet uses and gratifications: a structural equation model of interactive advertising," Journal of Advertising, vol. 34, no. 2, pp. 57-70, 2005.

[73] S. J. McMillan and J.-S. Hwang, "Measures of perceived interactivity: an exploration of the role of direction of communication, user control, and time in shaping perceptions of interactivity," Journal of Advertising, vol. 31, no. 3, pp. 29-42, 2002.

[74] E. Pantano, "Engaging consumer through the storefront: evidences from integrating interactive technologies," Journal of Retailing and Consumer Services, vol. 1, no. 28, pp. 149-154, 2016.

[75] M. G. Elmashhara and A. M. Soares, "The influence of atmospherics general interior variables on shoppers' emotions and behavior," The International Review of Retail, Distribution and Consumer Research, vol. 30, pp. 1-23, 2020.

[76] E. Pantano and G. Naccarato, "Entertainment in retailing: The influences of advanced technologies," Journal of Retailing and Consumer Services, vol. 17, no. 3, pp. 200-204, 2010.

[77] P. Lasinger and C. Bauer, "Situationalization, the new road to adaptive digital-out-of-home advertising," in Proceedings of the IADIS International Conference e-Society, pp. 162-169, Lisbon, Portugal, March 2013. 